\title{
RUSSIAN SECTION
}

That the Russian Section can from the very start take such an important place in our magazine, we owe chiefly to the courtesy and the kind assistance of His Excellency the Ambassador of the U.S.S.R. at the Hague and to the discernment of the First Secretary of the Embassy, Mr. P. Sliousarenko, who has spared no trouble to help us carry through this part of our program. Our respectful and cordial thanks are therefore due both to His Excellency and to Mr. Sliousarenko.

Translation of an introductory letter for Synthese from His Excellency the Ambassador of the U.S.S.R. at the Hague.

To the Editors of the Periodical Synthese.

I have great pleasure in welcoming the periodical Synthese at the moment when its publication is being resumed after having been suspended in consequence of the German agression.

With particular satisfaction I note that Synthese is opening a new section, devoted to the state of contemporary science in the U.S.S.R.

This initiative will doubtless contribute to the strengthening of the cultural and scientific ties between the scholars of the U.S.S.R. and the Netherlands.

I hope your important work will meet with great success.

Signed V. Valkov

Ambassador of the U.S.S.R.

to The Netherlands

Translation of a letter from the Vice-President of the

Section History, Economics and Philosophy of the VOKS (Moscow).

To the Editors of the Periodical Synthese.

The members of the Section History, Economics and Philosophy of the "Society for Cultural Relations between the Sowjet Union and Foreign Countries" comprising historians, archaeologers, ethnographers, anthropologists, linguists, jurists, economists, philosophers and psycho. logists, have noted with lively interest your intention to publish a Russian Section in your magazine Synthese. This measure will doubtless benefit the organisation and the strengthening of the cultural and particularly the scientific ties between the scholars of the U.S.S.R. and the Netherlands.

As an initial contribution to the Russian Section we are sending you an article written by the President of the U.S.S.R. Academy of Sciences, Mr. S. I. Vavilov, and we wish you in every respect success to this project.

The Vice-President of the Section History, Economics and Philosophy of the VOKS, signed V. I. Svetlov. 